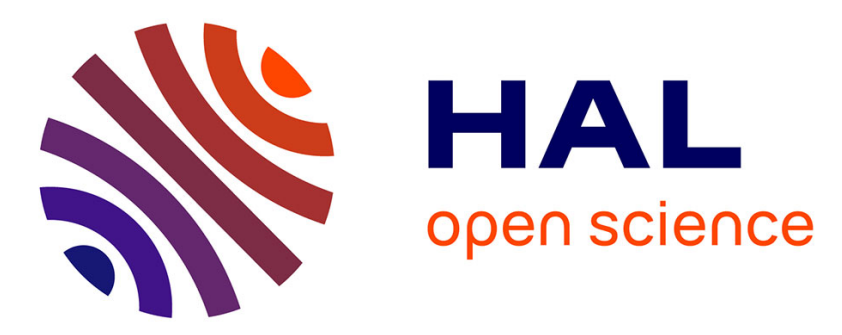

\title{
Transmission electron microscopy characterization of dislocations and slip systems in K-lingunite: Implications for the seismic anisotropy of subducted crust
}

\author{
A. Mussi, P. Cordier, D. Mainprice, D.J. Frost
}

\section{To cite this version:}

A. Mussi, P. Cordier, D. Mainprice, D.J. Frost. Transmission electron microscopy characterization of dislocations and slip systems in K-lingunite: Implications for the seismic anisotropy of subducted crust. Physics of the Earth and Planetary Interiors, 2010, 182 (1-2), pp.50. 10.1016/j.pepi.2010.06.013 . hal-00675799

\section{HAL Id: hal-00675799 \\ https://hal.science/hal-00675799}

Submitted on 2 Mar 2012

HAL is a multi-disciplinary open access archive for the deposit and dissemination of scientific research documents, whether they are published or not. The documents may come from teaching and research institutions in France or abroad, or from public or private research centers.
L'archive ouverte pluridisciplinaire HAL, est destinée au dépôt et à la diffusion de documents scientifiques de niveau recherche, publiés ou non, émanant des établissements d'enseignement et de recherche français ou étrangers, des laboratoires publics ou privés. 


\section{Accepted Manuscript}

Title: Transmission electron microscopy characterization of dislocations and slip systems in K-lingunite: Implications for the seismic anisotropy of subducted crust

Authors: A. Mussi, P. Cordier, D. Mainprice, D.J. Frost

PII:

S0031-9201(10)00133-0

DOI: doi:10.1016/j.pepi.2010.06.013

Reference: PEPI 5305

To appear in: $\quad$ Physics of the Earth and Planetary Interiors

Received date: $\quad$ 26-3-2010

Revised date: $\quad$ 7-6-2010

Accepted date: $\quad$ 21-6-2010

Please cite this article as: Mussi, A., Cordier, P., Mainprice, D., Frost, D.J., Transmission electron microscopy characterization of dislocations and slip systems in K-lingunite: Implications for the seismic anisotropy of subducted crust, Physics of the Earth and Planetary Interiors (2010), doi:10.1016/j.pepi.2010.06.013

This is a PDF file of an unedited manuscript that has been accepted for publication. As a service to our customers we are providing this early version of the manuscript. The manuscript will undergo copyediting, typesetting, and review of the resulting proof before it is published in its final form. Please note that during the production process errors may be discovered which could affect the content, and all legal disclaimers that apply to the journal pertain. 
1

2

3

4

5

6

7

8

9

10

11

12

\title{
Transmission electron microscopy characterization of dislocations and slip systems in K-
}

\section{lingunite: Implications for the seismic anisotropy of subducted crust}

\author{
A. Mussi ${ }^{*}{ }^{1}$, P. Cordier ${ }^{1,3}$, D. Mainprice ${ }^{2}$ and D.J. Frost ${ }^{3}$
}

Corresponding author = E-mail: alexandre.mussi@univ-lille1.fr; Fax number: +33 (0) 3204365 91; Telephone number: +33 (0) 320434960

${ }^{1}$ Unité Matériaux et Transformations, UMR 8207 CNRS-Université Lille1, Université Lille Nord de France, F-59655 Villeneuve d'Ascq, France

${ }^{2}$ Géosciences Montpellier, UMR CNRS 5243, Université Montpellier 2, Place Eugène Bataillon, 34095 Montpellier Cedex 5, France

${ }^{3}$ Bayerisches Geoinstitut, Universität Bayreuth, Germany.

\section{Abstract:}

In order to estimate the seismic anisotropy of subducted crust, polycrystalline samples of $\mathrm{KAlSi}_{3} \mathrm{O}_{8} \mathrm{~K}$-lingunite ( $25 \%$ of the total subducted transformed sediments), have been synthesized and deformed under the temperature and pressure conditions of the subducted slabs. Transmission Electron Microscopy (TEM) characterizations of the recovered samples reveal that the microstructures are clearly dominated by [001] glide involving screw dislocations. For this reason, only $\{100\}$ could be identified as glide planes, the question of [001] slip on $\{110\}$ remains open. Few $1 / 2<111>$ dislocations were observed gliding on $\{110\}$ planes, which implies that $1 / 2<111>\{110\}$ is a harder slip system than those involving [001] slip. The occurrence of sub-grain boundaries suggests that diffusion and climb might be active under these conditions.

To assess the texture of polycrystalline K-lingunite, the Crystal Preferred Orientations (CPO) were calculated using Visco-Plastic Self-Consistent (VPSC) polycrystalline plasticity model in simple shear using the slip systems identified by TEM. Finally, the seismic properties of K- 
lingunite aggregates were calculated from the CPO and single crystal elasticity tensor. Klingunite is predicted to have a high seismic anisotropy, which could combine constructively with the one of the stishovite (same proportion as K-lingunite at the transition zone depth ranges).

Keywords: K-lingunite, dislocation, slip systems, crystal preferred orientations, seismic properties

\section{Introduction}

The fate of subducted oceanic and continental crust in the mantle is of primary importance for the dynamics of the Earth. It depends largely on the rheological properties of the materials composing the slabs. The high-pressure behaviour of feldspars deserves attention since these minerals are a major component of the continental crust and since they host potassium, an important heat producing radionuclide. At ca. $9 \mathrm{GPa}, \mathrm{KAlSi}_{3} \mathrm{O}_{8}$ orthoclase transforms to a tetragonal polymorph with a hollandite structure (hereafter referred to as Klingunite since the hollandite structured $\mathrm{NaAlSi}_{3} \mathrm{O}_{8}$ has been previously named lingunite by Liu and El Goresy, (2007). The first synthesis and determination of the crystal structure of Klingunite (I4/m) was conducted by Ringwood et al. (1967). Yagi et al. (1994) and Urakawa et al. (1994) have further investigated its stability using in-situ X-ray diffraction and quench experiments. At higher pressure (ca. $20 \mathrm{GPa}$ ), K-lingunite transforms to an unquenchable monoclinic I2/m crystal structure at about $20 \mathrm{GPa}$ (Ferroir et al., 2006). Natural K-lingunite, has been identified in shock veins of heavily deformed ordinary chondrites (Gillet et al., 2000, Tomioka et al. 2000, Xie et al. 2001) and in the SNC achondrite Zagami (Langenhorst and Poirier, 2000a, b). Terrestrial silicate hollandite has also been reported in a strongly shocked 
anorthosite from the central uplift of the Manicouagan impact crater, Canada (Langenhorst \& Dressler (2003)).

Assessment of K-lingunite in subducted slabs requires the knowledge of the equation of state and elastic properties of this phase as a function of pressure. Zhang et al. (1993) have determined the compression behaviour of K-lingunite single crystals from ambient pressure up to $4.5 \mathrm{GPa}$. These results have been extended to higher pressure $(15-27 \mathrm{GPa})$ by Nishiyama et al. (2005). More recently, Mookherjee and Steinle-Neumann (2009) have calculated the elastic properties of K-lingunite up to $100 \mathrm{GPa}$, based on the density functional theory. Todate there is no data of plastic deformation of polycrystals of K-lingunite. However, the single crystal elastic properties cannot be transferred directly to the scale of the polycrystalline aggregate without knowing the Crystal Preferred Orientations (CPO). Plastic deformation by dislocation glide is one of the most efficient mechanisms to generate strong CPO. In this work, Transmission Electron Microscopy (TEM) characterizations of Klingunite specimens deformed at high pressure are performed to identify the deformation mechanisms of this phase. This information is used to model the CPO and the seismic properties of textured K-lingunite aggregates.

\section{Material and experimental procedure}

\subsection{High-pressure preparation and deformation of the samples}

K-lingunite was synthesized from a $\mathrm{KAlSi}_{3} \mathrm{O}_{8}$ glass in a multianvil press at $17 \mathrm{GPa}$ and at temperatures ranging from 1400 to $1600^{\circ} \mathrm{C}$. After synthesis in quasi-hydrostatic conditions, the high-pressure phase was recovered and placed in another high-pressure cell designed to induce deviatoric stresses during the compression (Cordier and Rubie, 2001), at $1300^{\circ} \mathrm{C}$, with the same pressure. The deformation conditions corresponding to this second run were $17 \mathrm{GPa}$, $1300^{\circ} \mathrm{C}$ for one hour (sample 3753) and one hour and a half (sample 2482). In this kind of 
experiments, large stresses applied during compression are relaxed at high temperature under pressure. After the run, the sample is quenched to ca. $100^{\circ} \mathrm{C}$ in a few seconds before the slow release of pressure.

\subsection{Transmission Electron Microscopy}

Two doubly polished thin foils were obtained from each high-pressure cell. They were thinned to electron transparency with a Gatan ${ }^{\circledR}$ DuoMill ${ }^{\mathrm{TM}}$ Model 600 ion milling device and lightly carbon coated. TEM investigations have been performed at a $300 \mathrm{kV}$ accelerating voltage with a Philips ${ }^{\circledR}$ CM30 microscope. As K-lingunite amorphises extremely rapidly under the electron beam damage, a Gatan ${ }^{\circledR}$ cold stage (liquid nitrogen temperature), a small condenser aperture $(100 \mu \mathrm{m})$ and a small spot size $(300 \mathrm{~nm})$, were used in order to preserve the sample long enough to perform the defects characterization. With such an electron illumination, the incident beam current and the fluence rate are respectively $14 \mathrm{nA}$ and $\underline{1.2 \times 10^{8} \text { electron. } \mathrm{nm}^{-2} \cdot \mathrm{s}^{-1} \text {, which can be considered as low dose irradiation conditions. }}$

The Precession Electron Diffraction (PED) procedure was employed to orientate the grains and to select diffraction vectors. As this technique scans the incident beam in association with a transmitted beam de-scan, at a constant angle throughout the optic axis (Vincent and Midgley, 1994), the spot intensities are reasonably associated with the structure factor and the multiple diffractions are reduced. Indeed, from Morniroli and Ji (2009), the forbidden spots by screw axis and glide plane become very weak for low precession angles and disappear when precession angles reach $3^{\circ}$ as in our case. Precession patterns are acquired with the "Spinning Star" device from the Nanomegas ${ }^{\circledR}$ Company. Dislocation Burgers vectors were characterized using the standard extinction conditions $(\mathbf{g} \cdot \mathbf{b}=0)$ as well as with the thicknessfringe method (Ishida et al. 1980, Miyajima and Walte 2009).

\section{Visco-plastic self-consistent model and seismic properties}


The Visco-Plastic Self-Consistent (VPSC) model has been established in Earth sciences by Wenk and co-workers (e.g. Wenk et al., 1991) as a model that provides a robust solution for the CPO development in mineral aggregates deforming by dislocation glide. The model was originally developed by Molinari et al. (1987) and extended to anisotropic materials by Lebensohn and Tomé (1993) and a recent review of the method is given by Tomé and Lebensohn (2004), thus only a short overview is presented in this section. This model has been successfully applied to many minerals of the Earth's mantle (e.g. olivine, Tommasi et al., 2000, wadsleyite, Tommasi et al., 2004, stishovite, Cordier et al., 2004).

The VPSC model is based on three assumptions: (i) the crystals that constitute the polycrystal deform uniquely by homogeneous intracrystalline slip, (ii) individual crystals obey a viscous rheology with shear strain rate proportional to shear stress raised to a power n, and (iii) the aggregate behaviour may be calculated as a volume average of the behaviour of the individual crystals. Locally, from crystal to crystal, stress and strain are heterogeneous and crystals, in an easy glide orientation, deform faster than those in low resolved shear stress orientations. Strain compatibility and stress equilibrium are ensured at the macroscopic scale, i.e. the polycrystalline stress $\left(\Sigma_{\mathrm{ij}}\right)$ and strain rate $\left(E_{\mathrm{kl}}\right)$ tensors are taken to be the volume average of the stress $\left(\sigma_{\mathrm{ij}}\right)$ and of the strain rates $\left(\varepsilon_{\mathrm{kl}}\right)$ tensors of the individual component crystals. The interaction between an individual crystal and a Homogeneous Effective Medium (HEM) (i.e. the polycrystalline aggregate) is treated using the inclusion formalism of Eshelby (1957), where each crystal is considered as an ellipsoidal inclusion. Eshelby has shown that the ellipsoidal inclusion has the unique property of having uniform internal stress, strain and strain rate fields. The uniform stresses and strain rates of the individual crystals are thus related to the macroscopic HEM polycrystalline quantities through,

$\varepsilon_{\mathrm{kl}}-E_{\mathrm{kl}}=-\alpha M_{\mathrm{ijkl}}\left(\sigma_{\mathrm{ij}}-\Sigma_{\mathrm{ij}}\right)$ 
where $M_{i j k l}$ is the interaction tensor which depends on the rheological properties of the polycrystal and the ellipsoidal shape of the inclusions. The constant $\alpha$ describes the interaction between crystals and the HEM, i.e. it imposes more or less stringent kinematics conditions on crystals. A zero value of $\alpha$ corresponds to the Taylor (1938) model (the upper mechanical bound approach) that imposes a homogeneous strain on all crystals (i.e. $\varepsilon_{\mathrm{kl}}=\mathrm{E}_{\mathrm{kl}}$ ) and requires that at least five independent slip systems are available. A value of one corresponds to the tangent VPSC model of Lebensohn and Tomé (1993), and an infinite value corresponds to the stress equilibrium model (i.e. the lower bound approach; Chastel et al., 1993). The VPSC and stress equilibrium models can operate with less than five independent slip systems, as locally strain compatibility is not required.

To perform a calculation model we need to define the initial CPO, the initial crystal shape, the interaction parameter $\alpha$, the power law stress exponent (n), a constant imposed velocity gradient tensor, a set of slip systems and their relative critical resolved shear stresses. Here we have taken the initial CPO to be composed of 1000 random individual orientations with spherical shape. We have chosen the standard tangent model with $\alpha=1$ for all simulations. We have no information about the stress exponent for K-lingunite from our experiments and we have assumed a value of 3 , which is typical of many minerals at high temperature. The VPSC model is not very sensitive to $\mathrm{n}$, between 3 and 5 , and almost all minerals have stress exponents in this range. Increasing $\mathrm{n}$ rises the degree of $\mathrm{CPO}$ for a given finite strain. In the present models, an aggregate of 1000 random orientations was deformed with a constant velocity gradient tensor for simple shear for 80 identical steps of 0.025 equivalent strain, giving a final equivalent strain of 2.0 (shear strain $\gamma=3.46$ ). The slip systems were determined by TEM, but we do not know their Critical Resolved Shear Stresses (CRSS). Based on the dislocation microstructure, we will propose the choice of CRSS. 


\section{Results}

\subsection{Dislocation observations and characterisation}

The specimen microstructure is heterogeneous. The grain size ranges from 45 to $85 \mu \mathrm{m}$ and some are free of dislocations. Nevertheless, most of them contain dislocations generated by plastic deformation. The density of free dislocations has been estimated of the order of $3.10^{12}$ $\mathrm{m}^{-2}$ using the method proposed by Ham (1961).

Figure 1.

The samples show pervasive evidence of low-angle sub-grain boundaries (Figure 1). In every image, the reflecting planes $\mathbf{g}$ and the Zone Axis (ZA) are indicated. Typical dislocation microstructures of the K-lingunite are shown in Figures 2 and 3. All the images in Figure 2, are from the same area, but each of them was acquired with different diffracting conditions. The dislocation population of Figure 2 is composed of two families: dislocations in sub-grain boundaries as well as free dislocations with $\rho \approx 3.10^{12} \mathrm{~m}^{-2}$. Both families of dislocations are out of contrast with the diffraction vector $\mathbf{g}=\overline{1} \overline{1} 0$ (Figure 2a). Moreover, following the method of Ishida et al. (1980), the value of the g.b product is $n=-1$ with $\mathbf{g}=4 \overline{5} 1$ (Figure $2 \mathrm{~b}$ ) and $\mathrm{n}=-1$ with $\mathbf{g}=0 \overline{3} 1$ (Figure $2 \mathrm{c}$ ). The analyses of the number of terminating fringes with Ishida's method are summarized in table 1. Consequently, the Burgers vector of these dislocations is $[00 \overline{1}]$.

Figure 2.

The dislocations visible in Figure 3 are in contrast with $\mathbf{g}=2 \overline{1} \overline{1}$, with a g.b product equal to $\mathrm{n}=-1$ (Figure 3a), and are standing end-on when viewed along [001] (Figure 3b). Considering other diffraction conditions, the Burgers vector of this family of dislocations is [001] and they have a screw character. Determining the glide plane of screw dislocations is difficult; however figure $3 b$ shows many [001] screw dislocations aligned perpendicular to 
$173[020]$ and to [200]. This observation suggests that ( 010$)$ and (100) may be glide planes for

174 [001] dislocations.

175

176

177

178

179

180

181

182

183

184
Figure 3.

Figure 4 shows two populations of dislocations, which exhibit different contrasts and terminating fringes:

- with $\mathbf{g}=\overline{3} 01$ (see Figure $4 \mathrm{a}$ ), the $\mathbf{g . b}$ product is $\mathrm{n}=-1$ for dislocations with the low contrast (labelled B) and $\mathrm{n}=2$ for the ones with a stronger contrast (labelled A);

- with $\mathbf{g}=00 \overline{2}$ (see Figure 4c), the g.b product is $\mathrm{n}=2$ for dislocations B and $\mathrm{n}=-1$ for dislocations A;

- then with $\mathbf{g}=\overline{2} 00$ (see Figure $4 \mathrm{~b}$ ), the g.b product is $\mathrm{n}=1$ for dislocations $\mathrm{A}$ and dislocations B are out of contrast.

Finally, the Burgers vector of dislocations $A$ is $1 / 2[\overline{1} 11]$ or $1 / 2[\overline{1} \overline{1} 1]$ and dislocations B are of the [001] type. From the orientations observed on figure 4c, the dislocations B have an edge character. This part of the specimen contains a comparable amount of $1 / 2<111>$ and [001] dislocations.

\section{Figure 4.}

Figure 5a shows a curved dislocation segment (circled). The number of terminating fringes suggests that $\mathrm{n}= \pm 2$ g.b product with $\mathbf{g}=\overline{2} 5 \overline{1}$. Considering other diffraction conditions, a Burgers vector of $\pm 1 / 2[11 \overline{1}]$ is consistent with all images obtained for this dislocation. The specimen has been tilted until this dislocation segment appears linear. This is achieved when the area is observed along the [001] zone axis. The segment appears to lie in the $(\overline{1} 10)$ plane (Figure 5b). Consequently, the slip system of the curved dislocation is $1 / 2$ [11 $\overline{1}](\overline{1} 10)$.

Figure 5. 
196

197

198

199

200

201

202

203

204

205

206

207

208

209

210

211

212

213

214

215

216

217

218

219

Figure 6a shows another curved dislocation for which diffraction experiments give a $\pm 1 / 2[\overline{1} 11]$ Burgers vector. Viewed along the [001] zone axis, this segment appears to lie in the (100) plane (Figure 6b).

Figure 6.

\subsection{Visco-plastic self-consistent modelling}

In order to run the VPSC models we need to define the CRSS for each slip system. The TEM analysis has shown that slip occurs on [001] $\{100\}$, the majority of the dislocations are [001] screw dislocations and these could potentially also slip on $\{110\}$ and indeed on all $\{\mathrm{hk} 0\}$. However, the TEM analysis did not unambiguously identify $\{110\}$ as active slip planes or effectively eliminates them either. As $[001]\{100\}$ dislocations had a high density we have assigned this slip system a low relative CRSS of one. The $[001]\{100\}$ system has probably a CRSS similar to [001] $\{110\}$, we have used a CRSS of one, but also of six to see how the activity of this system affects the CPO. A third slip system is observed, $1 / 2<111>\{110\}$, with a lower dislocation density. Without mechanical data, we have assigned a series of CRSS to this slip system between 1 and 6, assuming that it is less frequent because the shear stresses were only high enough to weakly activate the system. Four CRSS models were explored; all had the CRSS for $[001]\{100\}$ equal to one, but the values for $[001]\{110\}$ and $<111>\{110\}$ where either one or six. The results in Figure 7 show for the four CRSS models that the pole figures reveal very little change in the overall distribution and only slight variations of pole figure densities.

\section{Figure 7.}

The slip activity associated for the two CRSS models are shown in Figure 8. The [001]\{100\} has a high activity (0.4 to 0.8$)$ in all models. The $1 / 2<111>\{110\}$ slip system has moderate (0.3 to 0.2$)$ activities in all models even when the CRSS equals six. The $[001]\{110\}$ system 
has a bi-polar behaviour, if the CRSS equals one it has the same activity as [001] $\{100\}$, if the CRSS equals six, it has virtually zero activity.

Figure 8 .

\subsection{Seismic properties}

The high-pressure K-lingunite phase represents between 20 to 30 percent by volume of subducted and transformed argillaceous sediments. The anisotropic seismic properties at mantle pressures can be calculated using the CPO of K-lingunite, presented in Figure 9, and the single crystal elastic constants and pressure derivatives recently predicted, using firstprinciples by Mookherjee and Steinle-Neumann (2009). The seismic properties were calculated using the numerical methods described by Mainprice (1990; 2007). The properties were calculated at a pressure of $17 \mathrm{GPa}$, the pressure of the deformation experiments, which is approximately equivalent to a depth of $500 \mathrm{~km}$. At present, no temperature derivatives are available for the elastic constants. In Figure 9, the seismic properties are illustrated using:

- the P-wave velocity $(\mathrm{Vp})$ in $\mathrm{km} / \mathrm{s}$;

- anisotropy of the difference in velocity between the fastest and slowest shear wave (shear wave splitting), for a given propagation direction and (AVs) as percentage;

- $\quad$ and the polarization of the fastest shear wave.

The main features of the seismic anisotropy are a fast Vp velocity of $11.7 \mathrm{~km} / \mathrm{s}$ parallel to $\mathrm{X}$ and slow Vp velocity of $10.3 \mathrm{~km} / \mathrm{s}$ parallel to $\mathrm{Z}$. The shear-wave splitting is high in a broad region near the $\mathrm{Y}$ direction, normal to $\mathrm{X}$ and $\mathrm{Z}$ and low near $\mathrm{X}$. The $\mathrm{Vp}$ anisotropy is 12.8 percent, the AVs anisotropies are 15.1 percent for the CRSS model with all CRSS equal to one, the other models give nearly the same results. The orientation of fastest S-wave polarization is parallel to the XY plane

Figure 9.

\section{Discussion}




\subsection{Slip systems and deformation mechanisms}

The tetragonal cell of K-lingunite is very anisometric with [001] being much smaller than [100] or [010] (2.723 $\AA$ to be compared with $9.315 \AA)$. From the energetic point of view, it is expected that [001] dislocations are favoured since their elastic energy (which scales with $\left.\mu \mathrm{b}^{2}\right)$ is about ten times less than those of $<100>$ dislocations, supposing the $\mu_{[001]\{h k\}}$ shear modulus is nearly the same as the $\mu_{\langle 100\}\{0 k l\}}$ shear modulus. Our observations support this view since the large majority of observed dislocations are of the [001] type and no [100] or [010] dislocations could have been identified. From the crystal structure of K-lingunite, it is expected that [001] dislocations can glide in $\{100\}$ or $\{110\}$. Most free [001] dislocations have been shown to be of screw character rendering the identification of the slip planes difficult. The alignment of dislocations seen along the [001] zone axis suggests that [001] may have been activated in (010). However, the absence of evidence of [001] $\{110\}$ glide is not sufficient to rule out the possibility of this slip system.

The body-centered lattice (I) of K-lingunite (I4/m) induces an additional translation vector: $1 / 2[111]$. With a $6.726 \AA$ moduli, $1 / 2<111>$ dislocations have an elastic energy that corresponds to six times the one of [001] dislocations, supposing the $\mu_{\frac{1}{2}\langle 111\}\{110\}}$ shear modulus is nearly the same as the $\mu_{[001]\{100\}}$ shear modulus. The activation of $1 / 2<111>$ glide is pervasive in our samples. The $\{110\}$ planes have been identified as possible glide planes, in agreement with crystal structure considerations (Figure 10).

Figure 10.

We have also observed $\pm 1 / 2[\overline{1} 11]$ dislocations aligned along a (100) plane. Since this plane does not contain the Burgers vector, it must be considered as a climb plane. This is not the only evidence for climb since we have observed many sub-grain boundaries in several grains (some well-organized, some less). As already pointed out in previous studies (Cordier and 
Rubie 2001, Thurel and Cordier 2003), this kind of experiments, where specimens are compressed in a non-hydrostatic environment, correspond to high stresses at the beginning of the heating, which are then relaxed. After a given (unknown) time, the stress level becomes probably very low and recovery processes are enhanced. The large number of subgrain boundaries observed is thus not surprising. However, subgrain formation requires climb (also shown independently with $1 / 2<111>$ dislocations) and hence diffusion. Our observations are thus an indication that diffusion is active in $\mathrm{K}$-lingunite at $1300^{\circ} \mathrm{C}$.

\subsection{Modelling CPO of K-lingunite aggregates and seismic properties}

The VPSC models used the slip systems identified by TEM, namely [001] glide (in $\{100\}$ and possibly in $\{110\})$ and $1 / 2<111>\{110\})$. The dislocation density of [001] was higher and was dominated by dislocations of the screw character, which could result in "pencil" glide or cross-slip type behaviour on planes in the zone axis of the slip direction [001]. We assigned to this slip system the lowest CRSS of one. Simulations with all the four CRSS show that the CPO has the slip direction [001] parallel to the finite strain extension $\mathrm{X}$ direction, and the pole to (100) plane parallel to the finite strain shorting $\mathrm{Z}$ axis. In contrast, the $<111>$ direction and the pole to plane $\{110\}$ are oblique to $\mathrm{Y}$ and $\mathrm{Z}$ respectively. The pole figures suggest a dominant activity of [001] glide, which is confirmed by the slip system activity plots. The increase in the CRSS from one to six reduces the activity of the system $1 / 2<111>\{110\}$ to about $20 \%$, whereas the same increase for $[001]\{110\}$ reduces its activity to nearly zero. Reducing the activity of these glide systems is compensated by an increasing activity of $[001]\{100\}$. Pole figure densities and symmetries are virtually unaffected by these activity changes because slip in [001] direction is always dominant, either on the $\{100\}$ plane or a combination of $\{100\}$ and $\{110\}$ planes, which will produce pencil-like glide configuration because of tetragonal symmetry of K-lingunite. 
The seismic anisotropy calculated from the CPO for all CRSS models are also very similar, with:

- fast Vp parallel to X;

- the highest shear wave splitting anisotropy parallel to Y;

- and the fastest S-wave polarization parallel to the XY plane, plane of finite strain shortening normal to $\mathrm{Z}$.

At depth of $500 \mathrm{~km}$ in the lower part of the transition zone, slabs are often nearly horizontal (e.g. Fukao et al., 2001; Ritsema et al., 2004; Zhao 2004), and are very common in the circum-Pacific region. In such an idealized case, the horizontal propagation direction along X will have a high P-wave velocity and a low S-wave splitting, which would correspond to the down dip direction if the plate is slightly dipping. In contrast, the horizontal propagation direction along $\mathrm{Y}$ will have a moderate $\mathrm{P}$-wave velocity and a high S-wave splitting with a polarization of the fastest S-wave being parallel to the horizontal plate (XY) plane. If the plate has slightly dipped, then the polarization would also have a slight inclination in relation to the horizontal. The Y direction would correspond to the transverse direction of the plate, normal to the dip or to the subduction downward transport direction. These results can be compared with the results for stishovite VPSC models reported by Cordier et al. (2004) that we have recalculated at $17 \mathrm{GPa}$. These results show an almost identical orientation of the seismic pattern:

- $\quad$ high Vp parallel to X;

- $\quad$ high shear wave splitting parallel to Y;

- $\quad$ and the polarization of the fastest S-wave in the XY plane (Figure 9).

The anisotropy of $\mathrm{Vp}$ and $\mathrm{Vs}$ are $13.3 \%$ and $7.1 \%$ respectively in stishovite. These data can be compared with $12.8 \%$ and $15.1 \%$ for K-lingunite. Stishovite has a volume fraction of $25 \%$ at the transition zone depth ranges. Clearly, the anisotropy of K-lingunite and stishovite 
would constructively combine giving an effective volume fraction of about $50 \%$ of the transformed sediments. The other phases present are majorite $(30 \%)$, clinopyroxene $(5 \%)$ and CaAlSi-phase (15\%) (Irifune et al., 1994). Of these phases, only majorite is volumetrically important. The pure Mg end-member majorite of the majorite-pyrope garnet solid solution has tetragonal symmetry and is relatively weakly anisotropic with $1.8 \%$ for $\mathrm{Vp}$ and $9.1 \%$ for Vs (Pacalo and Weidner, 1997; Sinogeikin, S.V. and Bass, J.D., 2002a, b). Naturally deformed garnets do not have strong CPOs in eclogites (Mainprice et al., 2004). Nothing is known about majorite $\mathrm{CPO}$, but they are probably similar to the weak $\mathrm{CPO}$ of garnets and hence polycrystalline majorite will have isotropic seismic properties. It seems likely that the anisotropic seismic properties of subducted and transformed sediments will be dominated by the combined $50 \%$ volume fraction of anisotropic K-lingunite and stishovite.

Global studies of radial seismic anisotropy of the deep mantle have shown that in the transition zone (400-700 km depth), regions of subducted slab material are associated with Vsv > Vsh (e.g. Panning and Romanowicz, 2006; Visser et al., 2008). These global studies would probably not detect the anisotropy associated with a thin veneer of transformed sediments on the slab upper surface. If the anisotropy combined of the K-lingunite and stishovite contributes to the observation of the Vsv $>$ Vsh signal, then the slab would have an inclination of $45^{\circ}$ or more. This aspect seems unlikely for regions with horizontal slabs in the transition zone. However, regional studies of horizontal propagation paths in the mid mantle show that the fastest S-waves are polarized horizontally (Vsh > Vsv) (e.g. Chen and Brudzinski, 2003; Wookey et al., 2002; Wookey and Kendall, 2004). In this case the anisotropy of K-lingunite and stishovite could contribute to this signal, especially if the transformed sediment acted as a wave-guide.

\section{Conclusion}


The plastic deformation mechanisms of K-lingunite are strongly controlled by the plateshaped crystal structure. The very anisometric tetragonal unit cell strongly favours [001] slip. Most of the dislocations are [001] screws, which makes the determination of glide planes difficult. A secondary slip in $1 / 2<111>\{110\}$ has also been characterized with a low occurrence rate. Using the observed glide systems and VPSC model, the CPO of K-lingunite aggregates has been obtained. The texture of polycrystalline K-lingunite shows that the slip direction [001] is parallel to the slab strain X direction and the pole to (100) plane is parallel to the slab strain $\mathrm{Z}$ axis. On the contrary, the $<111>$ direction and the pole to $\{110\}$ plane are tilted from the $\mathrm{Y}$ and the $\mathrm{Z}$ slab axes respectively. The seismic properties of $\mathrm{K}$-lingunite aggregates at $17 \mathrm{GPa}$ were calculated according to these $\mathrm{CPO}$ and to the single crystal elasticity tensor. Considering that the subducted slab is only composed of K-lingunite, then:

- $\quad$ The P-waves are faster in parallel with the finite expending $\mathrm{X}$ direction (maximal $\mathrm{Vp}=$ $11.7 \mathrm{~km} / \mathrm{s}$ ) and are slower in parallel with the finite shorting $\mathrm{Z}$ direction (minimal $\mathrm{Vp}$ $=10.3 \mathrm{~km} / \mathrm{s})$;

- The S-wave anisotropy is characterized by a high shear wave splitting (15.1\%) in the finite flattening (XY) plane in the $\mathrm{Y}$ direction. The fastest S-waves have their polarization directions in the XY plane.

Actually, K-lingunite is $25 \%$ by volume of the subducted and transformed argillaceous sediments. The other present phases are stishovite (25\%), majorite (30\%), CaAlSi-phase (15\%) and clinopyroxene (5\%). It is expected that majorite has a weak CPO and a weak crystal anisotropy. The seismic anisotropy of the CaAlSi-phase and clinopyroxene phases can be neglected due to their small proportion. Only stishovite is likely to have a strong CPO and a strong single crystal anisotropy. Indeed, stishovite has roughly the same polycrystalline seismic anisotropy pattern than the K-lingunite one, which would combine constructively. Even if the transformed sediments correspond to a thin crustal layer of a thickness of few 
369 kilometres, they could act as an anisotropic wave-guide for seismic waves propagating

370 through the slab surface. At a $500 \mathrm{~km}$ depth, corresponding to the $17 \mathrm{GPa}$ of the experiments,

371 slabs are often horizontal; hence horizontally propagating seismic waves could sample the

372 transformed sediment anisotropy over long distances.

373

374 Acknowledgements

375 We thank H. Schulze for his support of preparation of the thin sections of the recovered

376 samples. The TEM national facility in Lille is supported by the CNRS (INSU) and the Conseil

377 Régional du Nord - Pas de Calais, France.

378 


\section{References}

Chastel, Y.B., Dawson, P.R., Wenk, H.R., Bennett, K., 1993. Anisotropic convection with implications for the upper mantle. J. Geophys. Res., 98, 17757-17771, doi:10.1029/93JB01161.

Chen W.P., Brudzinski, M.R., 2003. Seismic anisotropy in the mantle transition zone beneath Fiji-Tonga. Geophys. Res. Lett., 30, 15.1-15.4, doi:10.1029/2002GL016330.

Cordier, P., Rubie, D.C., 2001. Plastic deformation of minerals under extreme pressure using a multi-anvil apparatus. Mater. Sci. Eng. A 309-310, 38-43, doi:10.1016/S09215093(00)01795-0.

Cordier, P., Mainprice, D., and Mosenfelder, J.L., 2004. Mechanical instability near the stishovite $-\mathrm{CaCl}_{2}$ phase transition: implications for crystal preferred orientations and seismic properties. Eur. J. Mineral., 16, 387-399, doi:10.1127/0935-1221/2004/0016-0387.

Eshelby, J.D., 1957. The determination of the elastic field of an ellipsoidal inclusion, and related problems. Proc. R. Soc. London, 241, 376-396.

Irifune, T., Ringwood, A.E., Hibberson, W.O., 1994. Subduction of continental crust and terrigenous and pelagic sediments: An experimental study. Earth Planet. Sci. Letters 126, 351-368, doi:10.1016/0012-821X(94)90117-1.

Ferroir, T., Onozawa, T., Yagi, T., Merkel, S., Miyajima, N., Nishiyama, N., Irifune, T., Kikegawa, T., 2006. Equation of state and phase transition in K-hollandite at high pressure. Am. Mineral. 91, 327-332, doi:10.2138/am.2006.1879.

Fukao,Y., Widiyantoro,S., Obayashi,M., 2001. Stagnant slabs in the upper and lower mantle transition region, Rev. Geophys. 39, 291-323.

Gillet, P., Chen, M., Dubrovinsky, L., El Goresy, A., 2000. Natural NaAlSi3O8-hollandite in the shocked sixiangkou meteorite. Nature 287, 1633-1636, doi: 10.1126/science.287.5458.1633. 
403

404

405

406

407

408

409

410

411

412

413

414

415

416

417

418

419

420

421

422

423

424

425

426

Ham, R.K., 1961. The determination of dislocation densities in thin films. Phil. Mag. 6, 11831184, doi:10.1080/14786436108239679.

Ishida, Y., Ishida, H., Kohra, K., Ichinose, H., 1980. Determination of the Burgers vector of a dislocation by weak-beam imaging in a HVEM. Phil. Mag. A 42, 453-462, doi:10.1080/01418618008239369.

Langenhorst, F., Dressler, B., 2003. First observation of silicate hollandite in a terrestrial rock. In: Proceeding of the third international conference on Large meteorite impacts Geological Society of America Special Paper. Abstract - \#4046.

Langenhorst, F., Poirier, J.P., 2000a. Anatomy of black veins in Zagami: clues to the formation of high-pressure phases. Earth Planet. Sci. Lett. 184, 37-55, doi:10.1016/S0012$821 X(00) 00317-4$

Langenhorst, F., Poirier, J.P., 2000b. 'Eclogitic' minerals in a shocked basaltic meteorite. Earth Planet. Sci. Lett. 176, 259-265, doi: 10.1016/S0012-821X(00)00028-5.

Lebensohn, R.A., Tomé, C.N., 1993. A self-consistent anisotropic approach for the simulation of plastic deformation and texture development of polycrystals: application to zirconium alloys. Acta Met. Mater. 41, 2611-2624, doi:10.1016/0956-7151(93)90130-K.

Liu, L.G., El Goresy, A., 2007. High-pressure phase transitions of the feldspars and further characterization of lingunite. Inter. Geol. Rev. 49, 854-860, doi:10.2747/00206814.49 .9 .854

Mainprice, D., 1990. An efficient FORTRAN program to calculate seismic anisotropy from the lattice preferred orientation of minerals. Computers \& Gesosciences. 16,385-393.

Mainprice, D., 2007. Seismic anisotropy of the deep Earth from a mineral and rock physics perspective. In 'Treatise in Geophysics' Editor-in-Chief G.Schubert, Volume 2 'Mineral Physics’ Editor G.D.Price, pp 437-492. Oxford: Elsevier. 
Mainprice, D., Bascou, J., Cordier, P., Tommasi, A., 2004. Crystal preferred orientations of garnet: comparisons of numerical simulations with naturally deformed Ecolgites. J. Struct. Geol., 26, 2089-2102.

Miyajima, N., Walte, N., 2009. Burgers vector determination in deformed perovskite and post-perovskite of $\mathrm{CaIrO} 3$ using thickness fringes in weak-beam dark-field images. Ultramicroscopy 109, 683-692, doi:10.1016/j.ultramic.2009.01.010.

Molinari, A., Canova, G. R., Azhy, S., 1987. A self-consistent approach of the large deformation crystal polycrystal viscoplasticity. Acta Metall. 35, 2983-2994, doi:10.1016/0001-6160(87)90297-5.

Mookherjee, M., Steinle-Neumann, G., 2009. Detecting deeply subducted crust from the elasticity of hollandite. Earth Planet. Sci. Lett. 288, 349-358, doi:10.1016/j.eps1.2009.09.037.

Morniroli, J.P., Ji G., 2009. Identification of the kinematical forbidden reflections from precession electron diffraction. Mater. Res. Soc. Symp. Proc. 1184-GG01-03, doi:10.1557/PROC-1184-GG01-03.

Nishiyama, N., Rapp, R.P., Irifune, T., Sanehira, T., Yamazaki, D., Funakoshi, K., 2005. Stability and $\mathrm{P}-\mathrm{V}-\mathrm{T}$ equation of state of KAlSi3O8-hollandite determined by in situ X-ray observations and implications for dynamics of subducted continental crust material. Phys. Chem. Minerals 32, 627-637, doi:10.1007/s00269-005-0037-y.

Pacalo, R.E.G., Weidner, D.J., 1997. Elasticity of majorite, MgSiO3 tetragonal garnet, Phys. Earth Planet. Inter. 99, 145-154, doi:10.1016/S0031-9201(96)03158-5.

Panning M., Romanowicz B., 2006. Three-dimensional radially anisotropic model of shear velocity in the whole mantle. Geophysical Journal International 167: 361-379, doi:10.1111/j.1365-246X.2006.03100.x. 
Ritsema, J., van Heijst, H.-J., Woodhouse, J.H., 2004. Global transition zone tomography. J. Geophys. Res. 109 B02302, doi:10.1029/2003JB002610.

Ringwood, A.E., Reid, A.F., Wadsley, A.D., 1967. High-Pressure KAISi3O8, an Aluminosilieate with Sixfold Coordination. Acta Cryst. 23, 1093-1095, doi:10.1107/S0365110X6700430X.

Sinogeikin, S.V., Bass, J.D., 2002a. Elasticity of majorite and a majorite-pyrope solid solution to high pressure; implications for the transition zone, Geophys. Res. Lett. 29, 4.14.4, doi:10.1029/2001GL013937.

Sinogeikin, S.V., Bass, J.D., 2002b. Elasticity of pyrope and majorite-pyrope solid solutions to high temperatures, Earth Planet. Sci. Lett. 203, 549-555, doi:10.1016/S0012$821 \mathrm{X}(02) 00851-8$

Taylor, G.I., 1938. Plastic strain in metals. J. Inst. Met., 62, 307- 324.

Thurel, E., Cordier, P., 2003. Plastic deformation of wadsleyite: I. High-pressure deformation in compression. Phys. Chem. Minerals 30, 256-266, doi :10.1007/s00269-003-0312-8.

Tomé C.N., Lebensohn R., 2004. Self Consistent Homogenization Methods for Texture and Anisotropy. In Continuum Scale Simulation of Engineering Materials: Fundamentals Microstructures - Process Applications. Edited by D.Raabe, F.Roters, F.Barlat, and L.-Q. Chen J. Wiley \& Sons NY 2004 ISBN: 3-527-30760-5 pp462-489.

Tomioka, N., Mori, H., Fujino, K., 2000. Shock-induced transition of NaAlSi3O8. feldspar into a hollandite structure in a L6 chondrite. Geophys. Res. Lett. 27, 3397-4000, doi:10.1029/2000GL008513.

Tommasi, A., Mainprice, D., Canova, G., Chastel, Y. 2000. Viscoplastic selfconsistent and equilibrium-based modeling of olivine lattice preferred orientations. Implications for upper mantle seismic anisotropy, J. Geophys. Res., 105, 7893-7908. 
Tommasi, A., Mainprice,D., Cordier, P., Thoraval, C., Couvy, H., 2004. Strain-induced seismic anisotropy of wadsleyite polycrystals and flow patterns in the mantle transition zone, J. Geophys. Res., 109, B12405, doi:10.1029/2004JB003158.

Urakawa, S., Kondo, T., Igawa, N., Shimomura, O., Ohno, H., 1994. Synchrotron radiation study on the high-pressure and high-temperature phase relations of KAlSi3O8. Phys. Chem. Minerals 21, 387-391, doi:10.1007/BF00203296.

Vincent, R., Midgley, P.A., 1994. Double conical beam-rocking system for measurement of integrated electron diffraction intensities. Ultramicroscopy 53, 271-282, doi:10.1016/03043991(94)90039-6.

Wenk, H.-R., Bennett, K., Canova, G.R., Molinari, A., 1991. Modelling plastic deformation of peridotite with the self-consistent theory. J. Geophys. Res., 96, 8337-8349.

Visser, K., Trampert, J., Lebedev, S., Kennett, B.L.N., 2008. Probability of radial anisotropy in the deep mantle. Earth Planet. Sci. Lett. 270, 241-250, doi:10.1016/j.epsl.2008.03.041.

Wookey, J., Kendall, J.-M., Barruol,, G., 2002. Mid-mantle deformation inferred from seismic anisotropy. Nature 415, 777-780, doi:10.1038/415777a.

Wookey, J., Kendall, J.-M., 2004. Evidence of midmantle anisotropy from shear wave splitting and the influence of shear-coupled P waves. J. Geophys. Res. 109, B07309, doi:10.1029/2003JB002871.

Xie, X., Chen, M., Wang, D., El Goresy, A., 2001. NaAlSi3O8-hollandite and other highpressure minerals in the shock melt veins of the Suizhou meteorite. Chinese Sci. Bull., 46 1121-1126, doi:10.1007/BF02900692.

Yagi, A., Suzuki, T., Akaogi, M., 1994. High Pressure Transitions in the System KAISi3O8NaAISi3O8. Phys. Chem. Minerals 21, 12, doi:10.1007/BF00205210.

Zhang, J., Ko, J., Hazen, R.M., Prewitt, C.T., 1993. High-pressure crystal chemistry of KAISi308 hollandite. Am. Mineral. 78, 493-499. 
500 Zhao, D., 2004. Global tomographic images of mantle plumes and subducting slabs: insight

501 into deep Earth dynamics. Phys. Earth Planet. Inter. 146, 3-34, 502 doi:10.1016/j.pepi.2003.07.032.

503 
503

503 Table

504 Table 1 Reflecting planes $\mathbf{g}$ and g.b product with Ishida's method.

505 
505

506

507

508

509

510

511

512

513

514

515

516

517

518

519

520

521

522

523

524

525

526 Figure 6

527

528

Figure 5

\section{Figures captions}

Figure 1 Micrograph of sample 2482 in WBDF (Weak Beam Dark Field) condition (g= $0 \overline{3} 1$ ), along the [113] ZA. Four families of dislocations can be distinguished: \pm [001] dislocations in sub-grain boundaries, $\pm[001]$ free dislocations, $1 / 2<111>$ dislocations in sub-grain boundaries and $1 / 2<111>$ free dislocations.

Figure 2 Micrographs of sample 2482 in WBDF conditions showing only [00 $\overline{1}]$ dislocations with two examples of determination of $n=\mathbf{g} \cdot \mathbf{b}$ using the thickness fringes method. (a) Condition $\mathbf{g}=\underline{\overline{1}} \overline{1} 0$, along the $[\overline{1} 1 \overline{9}] \mathrm{ZA}$; (b) condition $\mathbf{g}=$ $4 \overline{5} 1$, along the $[\overline{1} 1 \overline{9}] \mathrm{ZA} ;$ (c) condition $\mathbf{g}=0 \overline{3} 1$, along the [1 515$] \mathrm{ZA}$.

Figure 3 WBDF pictures of sample 3753 obtained with $\mathbf{g}=2 \overline{1} \overline{1}$, along the [315] ZA (a) and $\mathbf{g}=020$, along the [001] ZA (b). These micrographs show numerous $[00 \overline{1}]$ dislocations with one example of determination of $n=$ g.b using the thickness fringes method.

Figure 4 WBDF images of sample 2482 with $\mathbf{g}=\overline{3} 01$, along the $[010]$ ZA (a); $\mathbf{g}=$ $\overline{2} 00$, along the [010] ZA (b) and $\mathbf{g}=00 \overline{2}$, along the [010] ZA (c). Micrographs revealing $1 / 2[\overline{1} 11]$ or $1 / 2[\overline{1} \overline{1} 1]$ dislocations and [ $00 \overline{1}]$ edge dislocations; with five examples of determination of $n=$ g.b using the thickness fringes method. WBDF images of sample 3753 showing a curved dislocation along the [1 $\overline{1} \overline{7}]$ $\mathrm{ZA}$, with $\mathbf{g}=\overline{2} 5 \overline{1}$ (a) and the glide plane along the [001] ZA, with $\mathbf{g}=0 \overline{2} 0$ (b).

WBDF images of sample 3753 showing a curved dislocation along the [001] $\mathrm{ZA}$, with $\mathbf{g}=\overline{2} 00$ (a) and the climb plane along the [315] ZA, with $\mathbf{g}=1 \overline{3} 0$ (b). 
Figure 7

Crystal preferred orientation of K-lingunite in simple shear. Model CRSS are marked on the figures. Shear strain $(\gamma)$ is 1.73 (Von Mises equivalent strain of 1.0). Maximum and minimum finite strain axes are marked $X$ and $Z$. The horizontal black line is the $\mathrm{XY}$ flattening plane or foliation. Thick black arrows mark the dextral shear sense, SD is the shear direction and the inclined red line is the shear plane. Lower hemisphere equal area projection.

Figure 8 Polycrystalline plastic anisotropy indicated by the slip systems activity as a function of model CRSS in simple shear with $[001]\{100\},[001]\{110\}$ and $<111>\{110\}$ slip systems. Model A: all slip systems have the same CRSS, corresponding to an isotropic plastic model. Model B: this model has a CRSS of $<111>\{110\}$ six times greater than $[001]\{100\}$ and $[001]\{110\}$. Model C: it has a CRSS of $[001]\{110\}$ six times greater than $[001]\{100\}$ and $<111>\{110\}$. Model D: it has a CRSS of $[001]\{110\}$ and $<111>\{110\}$ six times greater than $[001]\{100\}$.

Figure 9 The predicted seismic anisotropy at the pressure of $17 \mathrm{GPa}$, which corresponds to a $500 \mathrm{~km}$ depth. Above: it is composed of $100 \%$ polycrystalline K-lingunite with the CPO given in Figure 7 at shear strain of 1.73 for the horizontal flow (XY horizontal plane). The single crystal elastic constants given by Mookherjee and Steinle-Neumann (2009) have been used. Below: it is composed of $100 \%$ polycrystalline stishovite with the CPO given in Cordier et al.2004. Horizontal flow (XY horizontal plane). X, Y and Z are the principle finite strain axes where $\mathrm{X}>\mathrm{Y}>\mathrm{Z}$. The black horizontal line is the $\mathrm{XY}$ plane of finite strain. Lower hemisphere equal area projection. 
552 Figure 10 Projection of the K-lingunite crystal structure along the [001] direction, on the

553 left, and along the [111] direction, on the right ( $\mathrm{K}$ is symbolized by dark grey

554 spheres, Al octahedral and Si octahedral units are bright grey, with oxygen

555 atom in black). The $(100),(010),(110)$ and $(1 \overline{1} 0)$ glide planes are 556 represented.

557 


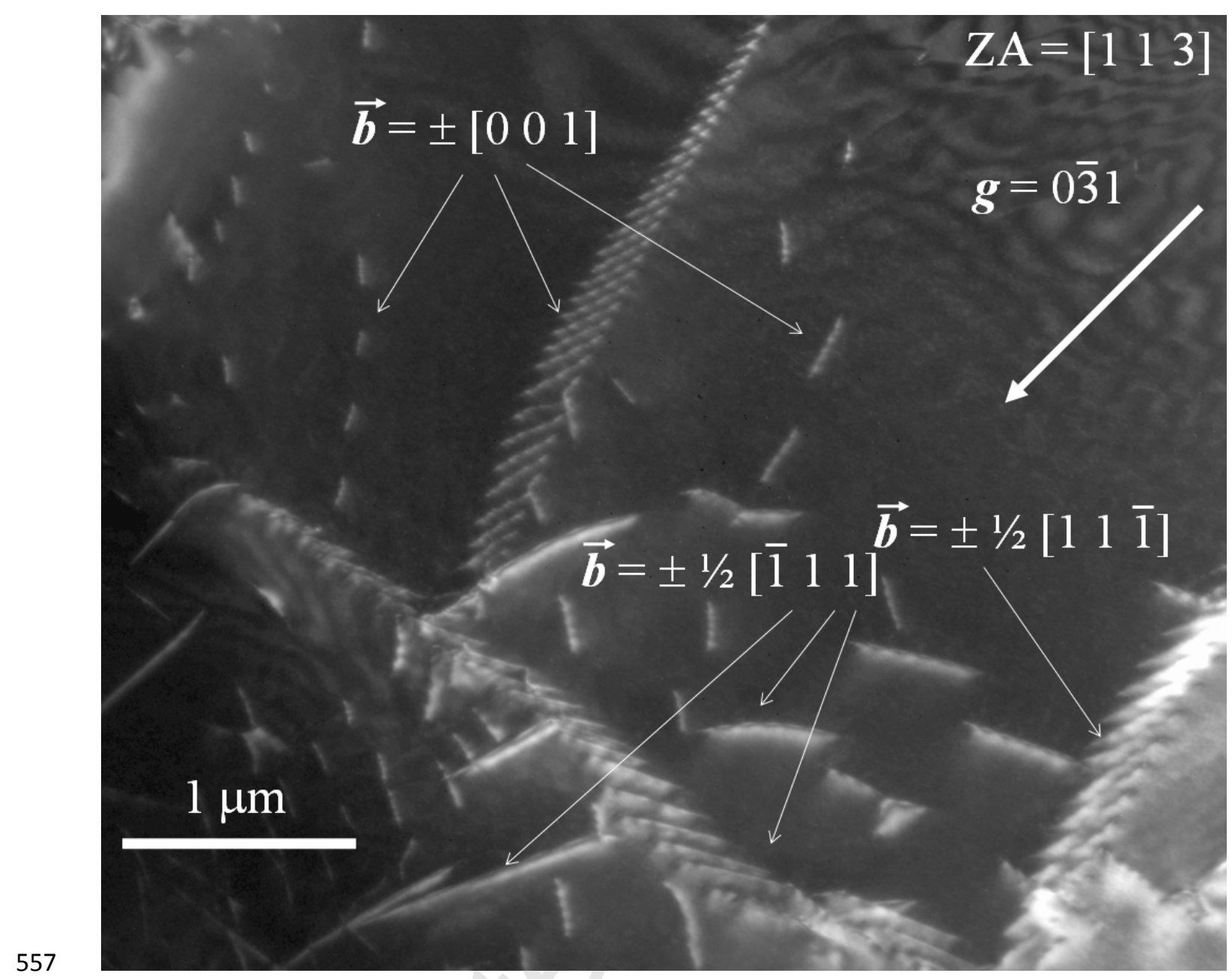

558

Figure 1.

559

560

561

562

563 


$$
\mathrm{ZA}=\left[\begin{array}{lll}
\overline{1} & 1 & \overline{9}
\end{array}\right]
$$
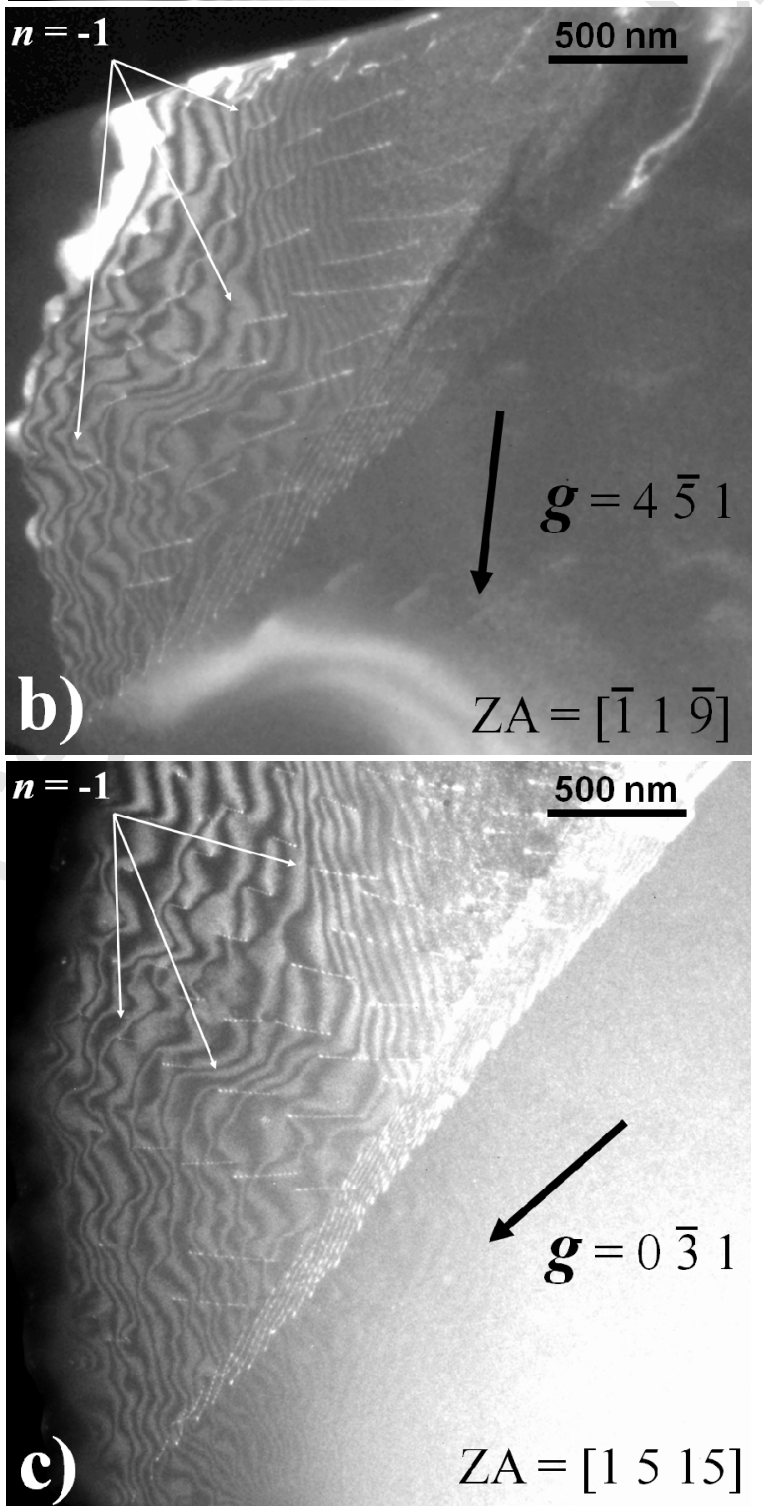
Figure 2.

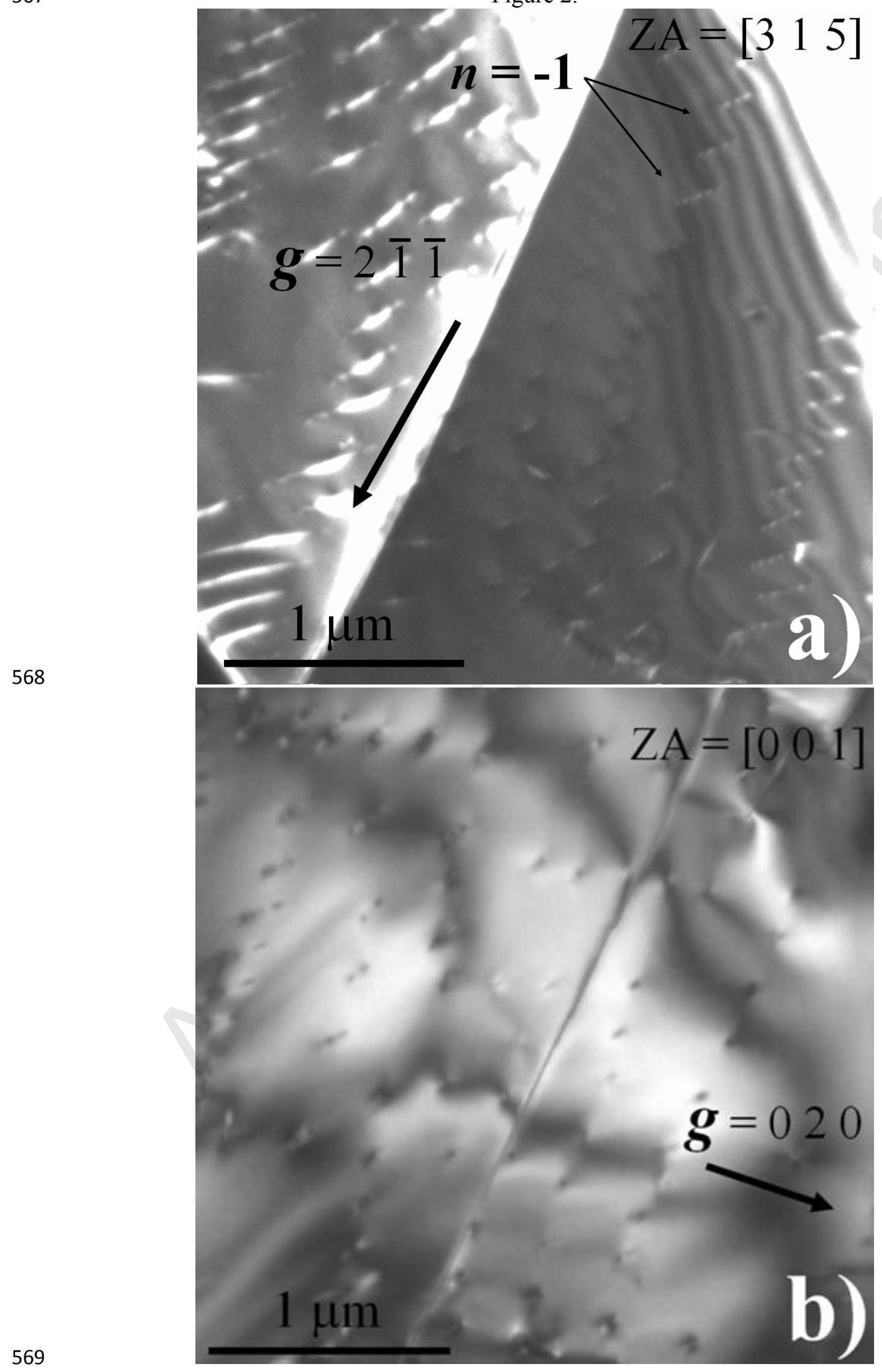


573

574

575

576

577
Figure 3.
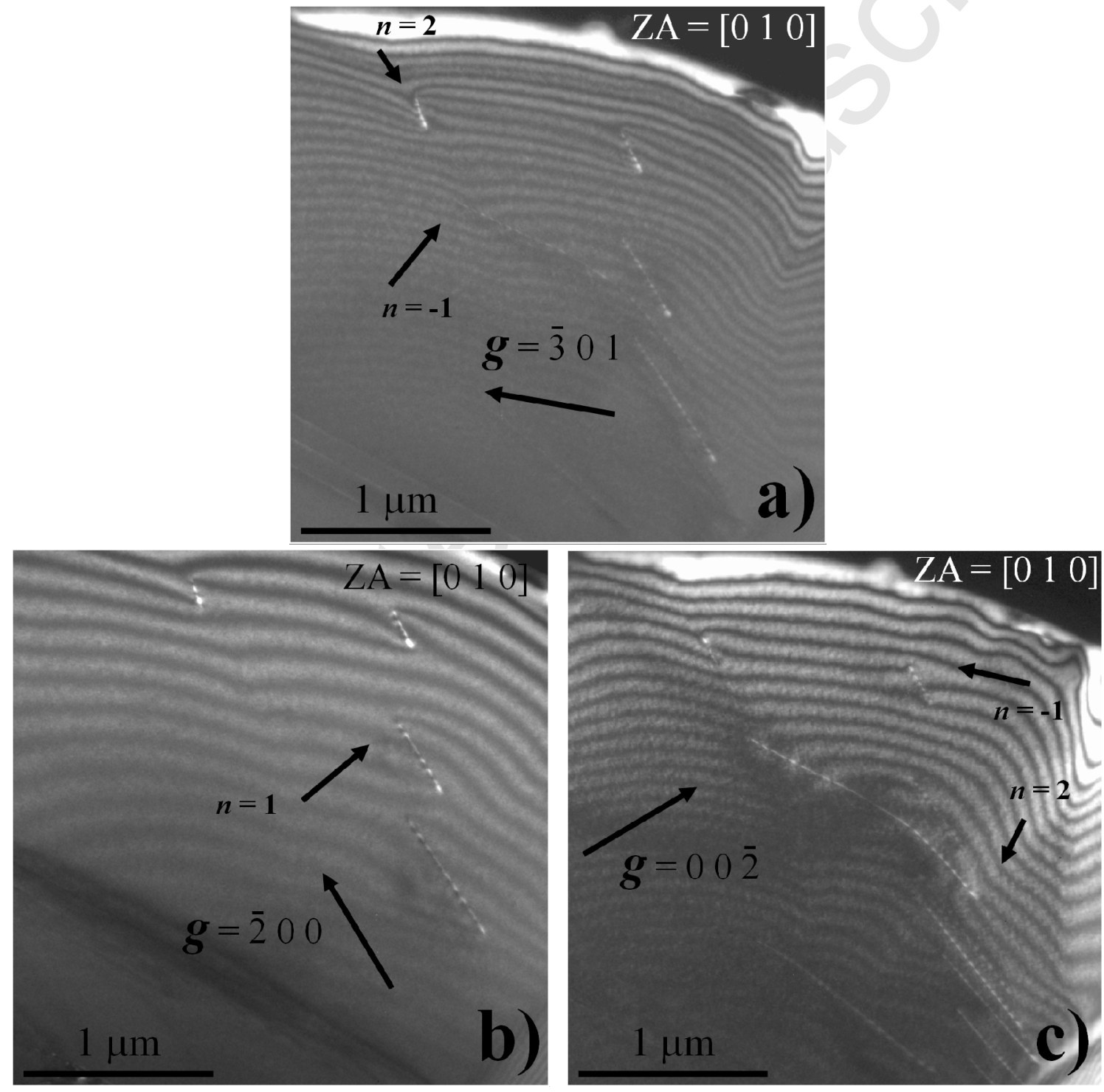

Figure 4. 


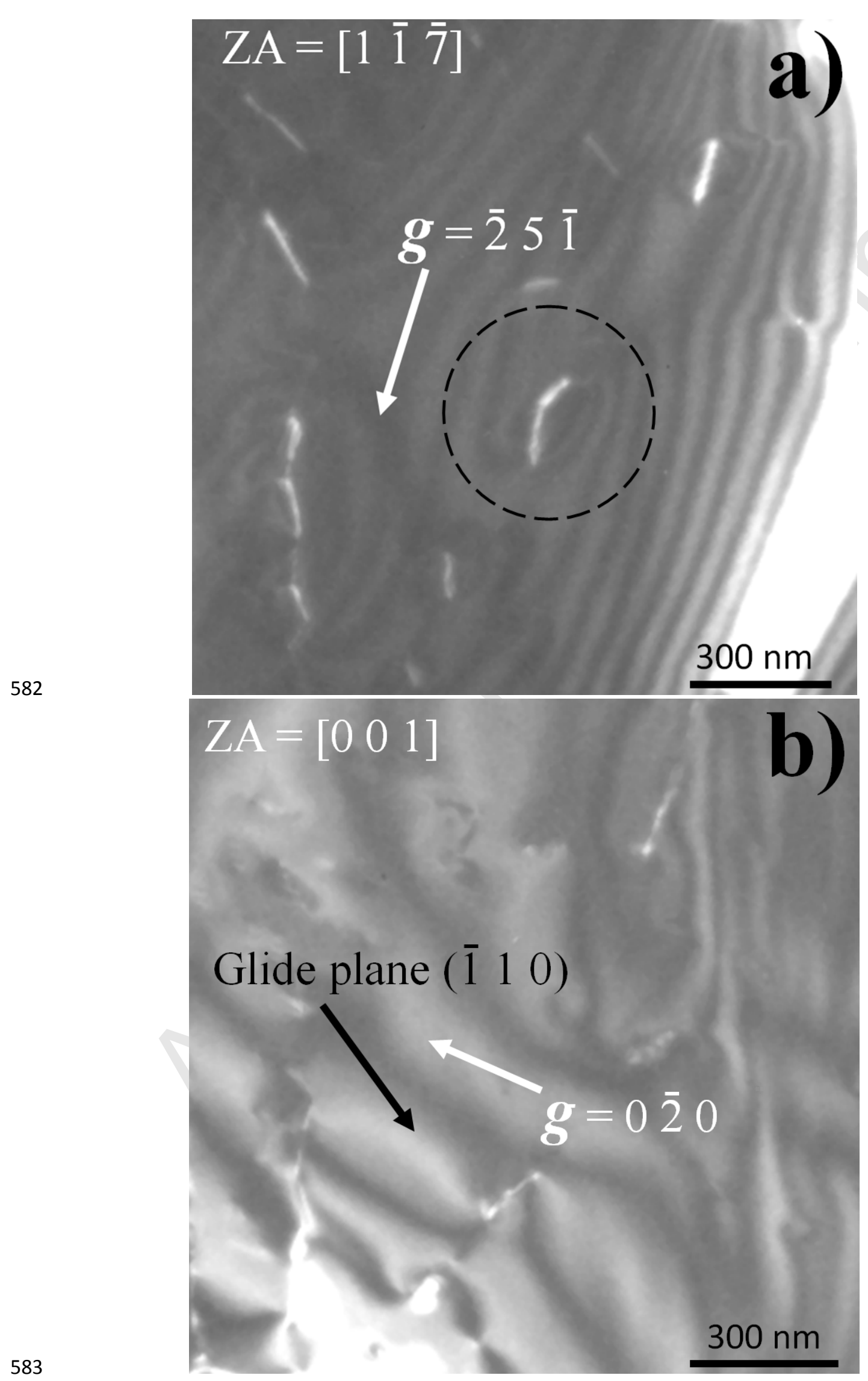


Figure 5.

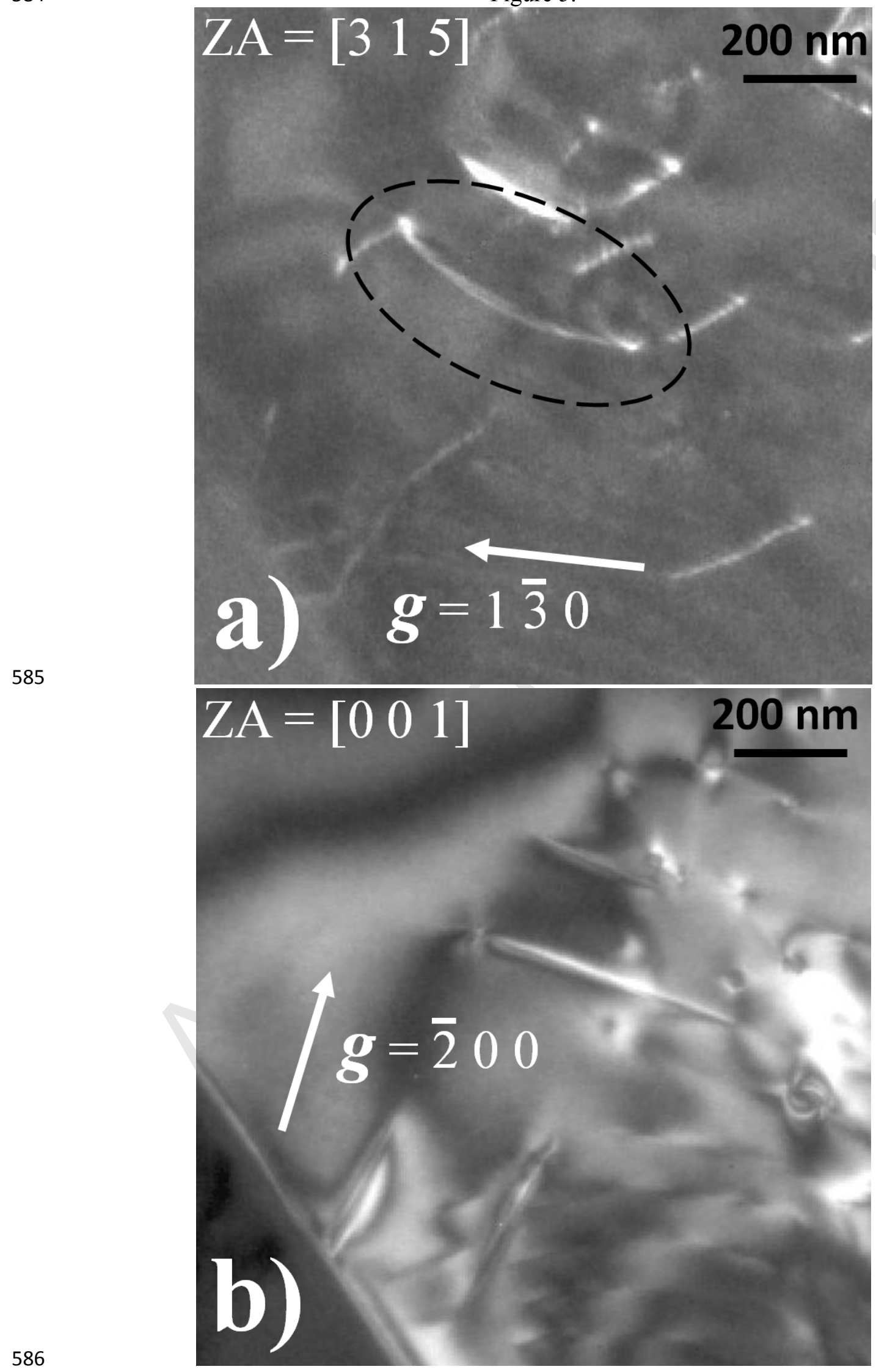


$\left[\begin{array}{lll}0 & 0 & 1\end{array}\right]\left\{\begin{array}{lll}1 & 0 & 0\end{array}\right\}$ CRSS $=1$ $\left[\begin{array}{lll}0 & 0 & 1\end{array}\right]\left\{\begin{array}{lll}1 & 1 & 0\end{array}\right\} C R S S=1$ $<\begin{array}{lll}1 & 1 & 1\end{array}\left\{\begin{array}{lll}1 & 1 & 0\end{array}\right\}$ CRSS $=1$

$\left[\begin{array}{lll}0 & 0 & 1\end{array}\right]\left\{\begin{array}{lll}1 & 0 & 0\end{array}\right\}$ CRSS $=1$ $\left[\begin{array}{lll}0 & 0 & 1\end{array}\right]\left\{\begin{array}{lll}1 & 1 & 0\end{array}\right\}$ CRSS $=1$ $\left.<\begin{array}{lll}1 & 1>\left\{\begin{array}{ll}1 & 1\end{array}\right\}\end{array}\right\}$ CRSS $=6$

$\left[\begin{array}{llll}0 & 0 & 1\end{array}\right]\left\{\begin{array}{llll}1 & 0 & 0\end{array}\right\}$ CRSS $=1$ [lllll $\left.\begin{array}{llll}0 & 1\end{array}\right]\left\{\begin{array}{lll}1 & 1 & 0\end{array}\right\}$ CRSS $=6$ $\left.<\begin{array}{lll}1 & 1>\left\{\begin{array}{ll}1 & 1\end{array}\right\}\end{array}\right\}$ CRSS $=1$

$\left[\begin{array}{lll}0 & 0 & 1\end{array}\right]\left\{\begin{array}{lll}1 & 0 & 0\end{array}\right\}$ CRSS $=1$ $\left[\begin{array}{lll}0 & 0 & 1\end{array}\right]\left\{\begin{array}{lll}1 & 1 & 0\end{array}\right\}$ CRSS $=6$ $<\begin{array}{lll}1 & 1>\left\{\begin{array}{lll}1 & 1 & 0\end{array}\right\} \text { CRSS }=6\end{array}$ $\left\{\begin{array}{lll}1 & 1 & 0\end{array}\right.$
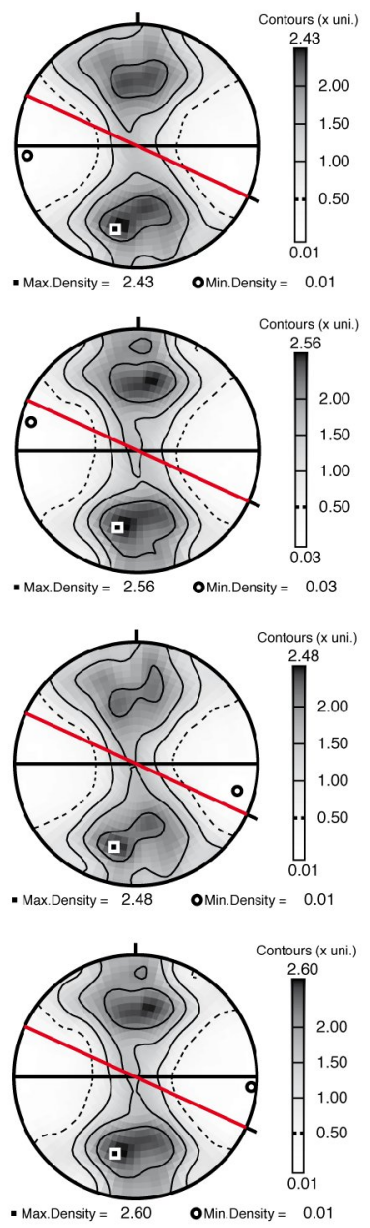

[0 001$]$
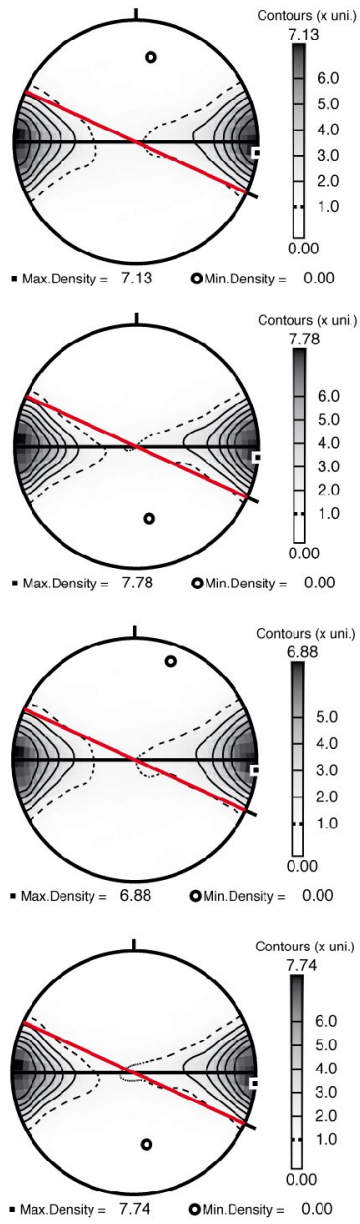

Figure 7. 

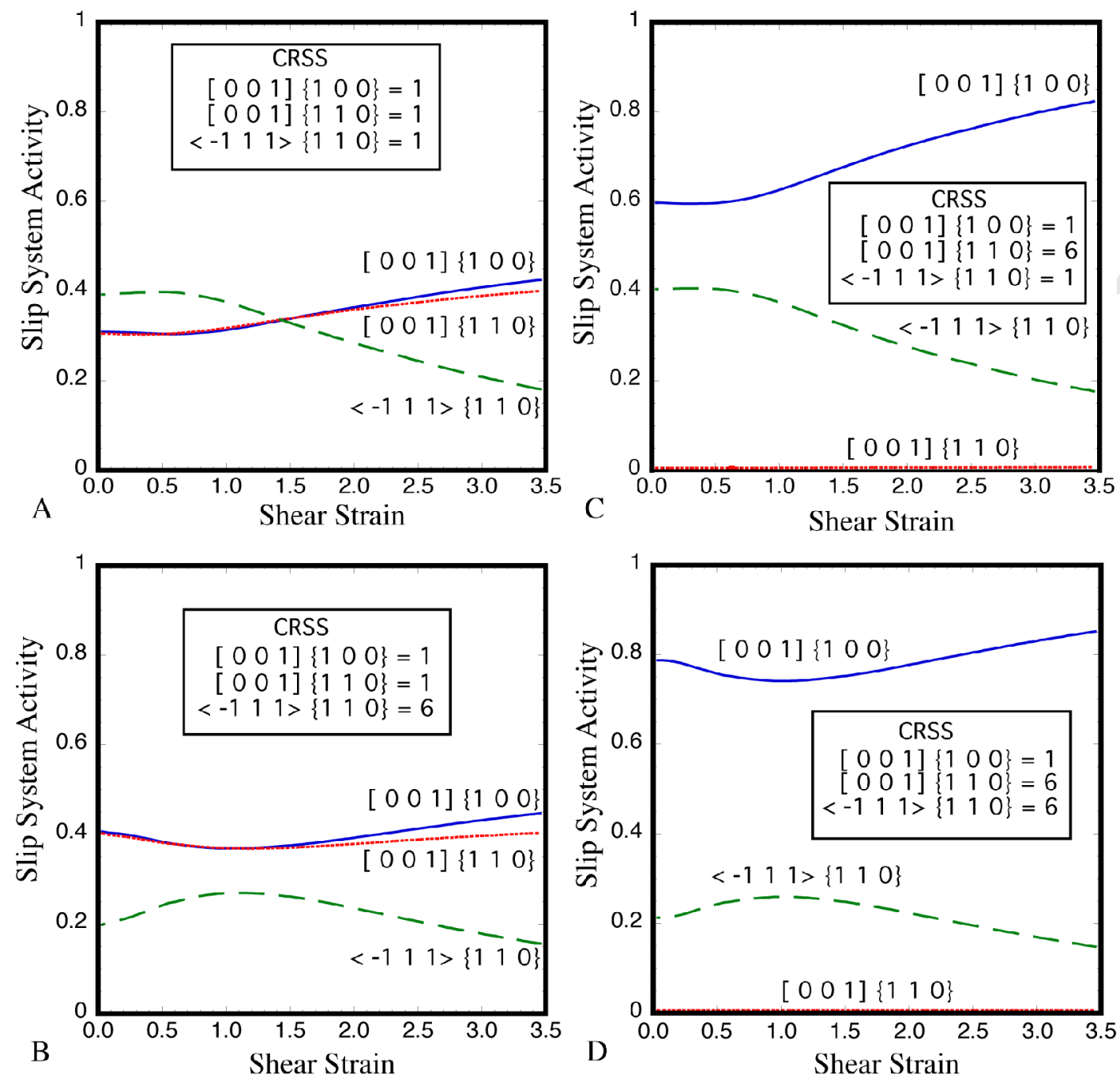

Figure 8 . 

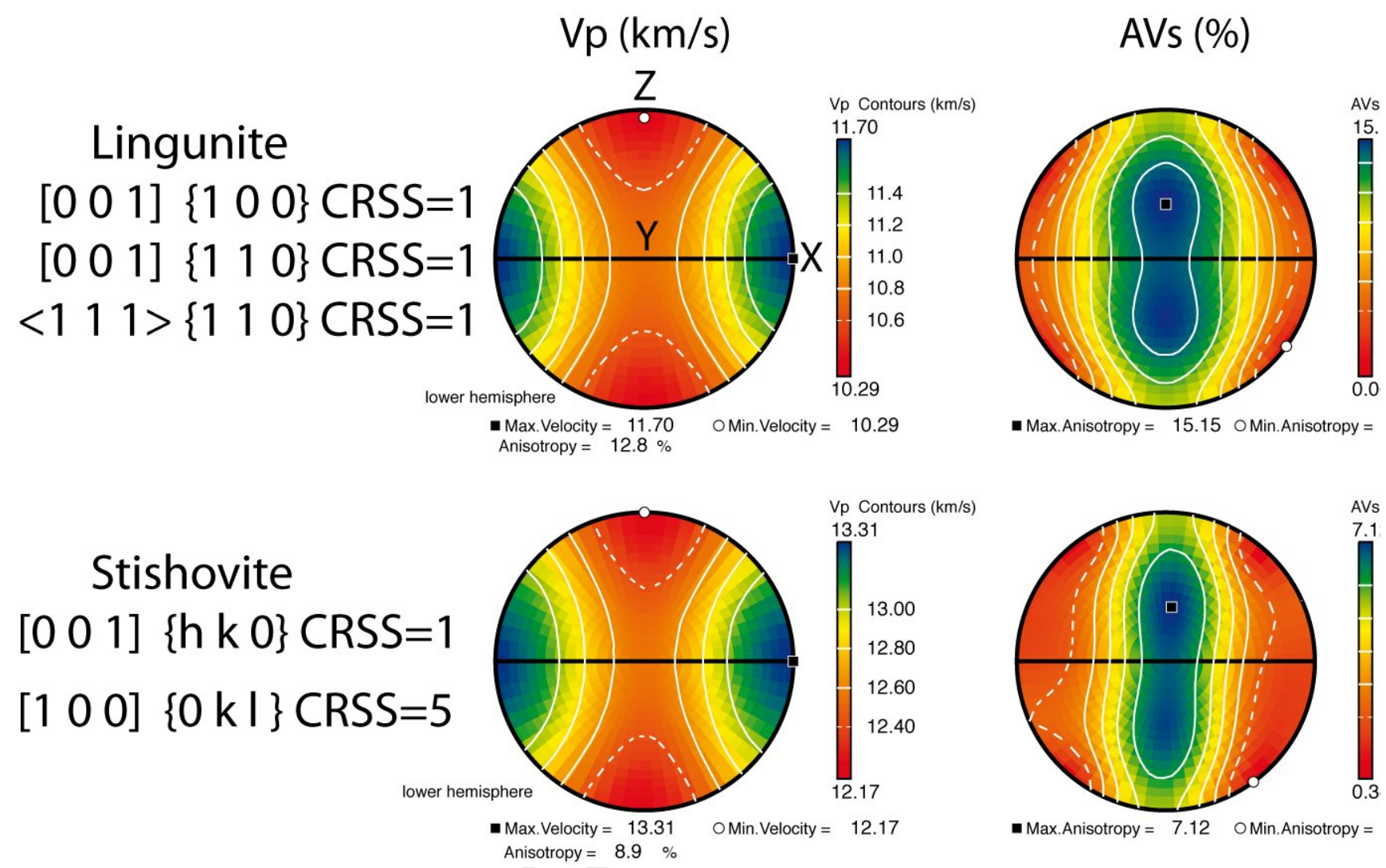

Figure 9. 

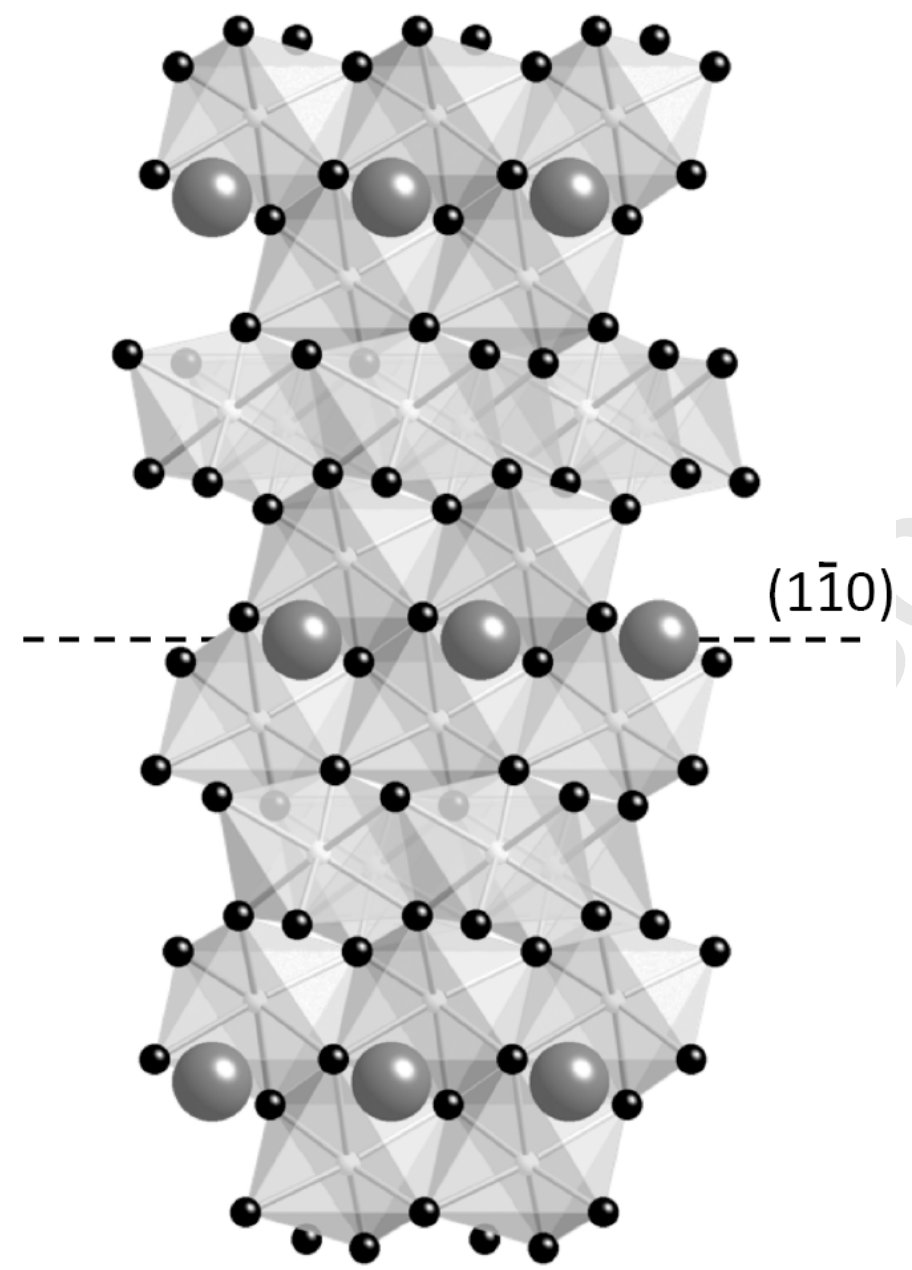

601

602

Figure 10.

603 


603
604
605
606
607
608
609
610
$611 \quad$ Table
$612 \quad$ Table 1

613

614

615 